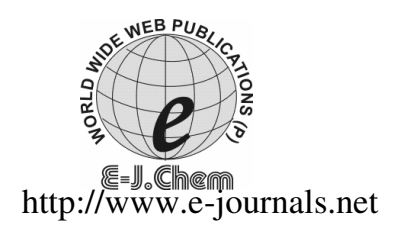

ISSN: 0973-4945; CODEN ECJHAO

E-Journal of Chemistry

2012, 9(1), 323-329

\title{
Spectrophotometric Determination of Antidepressant Drug Duloxetine in Pharmaceutical Preparations using $\pi$-Acceptors
}

\author{
SIDIKA ERTÜRK TOKER* ${ }^{*}$ and ARMAĞAN ÖNAL \\ Istanbul University, Faculty of Pharmacy \\ Department of Analytical Chemistry, 34116, Beyazit, Istanbul - Turkey \\ serturk@yahoo.com
}

Received 24 May 2011; Accepted 16 July 2011

\begin{abstract}
In this study, two simple and accurate spectrophotometric methods were presented for the determination of duloxetine hydrochloride (DLX) in pharmaceutical preparations. The methods were based on the reaction of DLX as $n$-electron donor with 2,3-dichloro-5,6-dicyano-1,4-benzoquinone (DDQ) and 7,7,8,8-tetracyanoquinodimethane (TCNQ) as $\pi$-acceptors to give highly colored complex species. The colored products were quantitated spectrophotometrically at 477 and 841 for DDQ, TCNQ, respectively. All variables were studied in order to optimize the reaction conditions. Beer's law was obeyed in the concentration ranges 10.0-50.0 and 15-60 $\mu \mathrm{g} \mathrm{mL}^{-1}$ for DDQ and TCNQ method, respectively. The proposed methods have been successfully applied to the pharmaceutical analysis without any interference from excipients. The suggested procedures could be used for the determination of DLX in pharmaceutical preparations being sensitive, simple and selective.
\end{abstract}

Keywords: Duloxetine, Charge-transfer Reaction, DDQ, TCNQ, Pharmaceutical preparations

\section{Introduction}

Duloxetine hydrochloride (DLX) [(+)-(S)- $N$-methyl-3-(1-naphthalenyloxy)-2-thiophenepropanamine hydrochloride, Figure 1, acts as a dual serotonin and norepinephrine reuptake inhibitor. It has been clinically used for the treatment of major depressive disorder, with or without melancholic symptoms, pain due to diabetic peripheral neuropathy and urinary incontinence $^{1-6}$.

To the best of our knowledge, only three papers can be found in the literature about determination of duloxetine at pharmaceutical preparations, which were based on UV spectrophotometric, high-performance thin layer chromatographic and high-performance liquid chromatographic analysis ${ }^{7-9}$. There is no visible spectrophotometric method available 
for determination of DLX in tablets; therefore two visible spectrophotometric analyses were developed for analysing of DLX in tablets. The methods were based on charge transfer reaction with 2,3-dichloro-5,6-dicyano-1,4-benzoquinone(DDQ) and 7,7,8,8-tetracya-noquinodimethane (TCNQ). A significant advantage of spectrophotometric methods unlike HPTLC or HPLC methods, the instrument is simple and is not of high cost. The sensitivity in terms of molar absorptivity and the precision of the proposed methods are better than UV spectrophotometric method. Because of the wide applicability of proposed methods, these are suggested for routine quality control assay of the drugs in pure form and its pharmaceutical preparations.

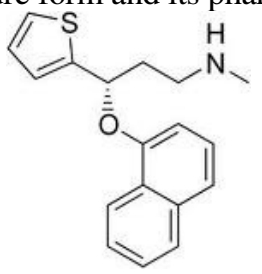

\section{Experimental}

Figure 1. Chemical structure of duloxetine

Spectrophotometric measurements were carried out using a Shimadzu UV-160A spectrophotometer with $1 \mathrm{~cm}$ glass cells.

\section{Reagents and solutions}

Duloxetine hydrochloride was kindly supplied by boehringer ingelheim pharma $\mathrm{GmbH}$ \&Co. KG (Germany). Its pharmaceutical preparation cymbalta capsul®, containing $60 \mathrm{mg}$ of duloxetine (DLX) per capsul and were obtained from local drugstore. All chemicals and reagents were of analytical-reagent grade.

Stock solutions were prepared by dissolving equivalent $25 \mathrm{mg}$ of duloxetine base in a $100 \mathrm{~mL}$ volumetric flask to give a concentration of $250 \mu \mathrm{g} \mathrm{mL}^{-1}$ of DLX. For this purpose, $10 \mathrm{~mL}$ aliquot of the stock solution was transferred to stoppered tube and $1 \mathrm{~mL} 1 \mathrm{~N} \mathrm{NaOH}$ solution was added. Three $5 \mathrm{~mL}$ portion of chloroform was added for the extraction. Combined extracts were dried using anhydrous $\mathrm{Na}_{2} \mathrm{SO}_{4}$ and diluted with $20 \mathrm{~mL}$ with chloroform. All of this solution was evaporated to dryness under nitrogen with mild heating. The residue was dissolved with acetonitrile (in $20 \mathrm{~mL}$ volumetric flask) using an ultrasonic bath. Acetonitrile was added to the mark ( $125 \mu \mathrm{g} \mathrm{mL}^{-1}$ as the base).

2,3-Dichloro-5,6-dicyano- $p$-benzoquinone (DDQ) (Merck-Schuchardt, Munich, Germany) was freshly prepared as $(0.2 \%(\mathrm{w} / \mathrm{v}))$ solutions in acetonitrile; the solution was stable for 1 week at $4{ }^{\circ} \mathrm{C}$. TCNQ was obtained from Merck (Darmstadt, Germany). 0.2\% TCNQ solution was prepared in acetonitrile.

\section{General procedure}

Into $10 \mathrm{~mL}$ calibrated flasks were placed $0.80-4.0 \mathrm{~mL}$ and $1.2-4.8 \mathrm{~mL}$ aliquots of $\mathrm{DLX}$ standart solution for DDQ and TCNQ method, respectively. The volume was bring to $4.0 \mathrm{~mL}$ (for DDQ) and $4.8 \mathrm{~mL}$, (for TCNQ) with acetonitrile and $3.5 \mathrm{~mL}$ of DDQ or $3 \mathrm{~mL}$ of TCNQ reagent solution was added. The reaction mixture was heated for $20 \mathrm{~min}$ at $60{ }^{\circ} \mathrm{C}$ for DDQ and allowed to stand for $5 \mathrm{~min}$ at room temperature for TCNQ method. After cooling and diluting to volume $10 \mathrm{~mL}$ with acetonitrile the absorbance was measured at 477 and $841 \mathrm{~nm}$ for DDQ and TCNQ, respectively, against a reagent blank prepared in the same manner. The calibration graph was prepared by plotting absorbance $v s$. concentration of pregabalin. 


\section{Assay procedure for pharmaceutical preparations}

The contents of 20 capsules were mixed and accurately weighed amount of the contents equivalent to $10 \mathrm{mg}$ of DLX was transferred into a $100 \mathrm{~mL}$ volumetric flask. About $50 \mathrm{~mL}$ of water was added and then extraction was performed mechanically for 20 minutes and sonicated for 20 more minutes. The volume was brought to $100 \mathrm{~mL}$ with water and final solution was filtered. Aliquots of filtrate were studied as described under preparation of General procedure. The nominal contents of the capsules were calculated using either the calibration graph or the corresponding regression equation.

\section{Results and Discussion}

As to our best knowledge, visible spectrophotometric determination of DLX in tablets has not been yet described. Therefore, two visible spectrophotometric analyses were developed for the determination of DLX in tablets. The developed methods are based on the reaction of DLX as $n$-electron donor with 2,3-dichloro-5,6-dicyano-1,4-benzoquinone (DDQ) and 7,7,8,8-tetracyanoquinodimethane (TCNQ) as a $\pi$-acceptor to give highly colored complex species. $\pi$-acceptors are known to yield charge transfer complexes and radical anions with a variety of electron donors ${ }^{10-15}$.

The interaction of DLX with DDQ and TCNQ, in acetonitrile yielded intense orange red colored chromogen for DDQ, a bluish-green colored chromogen for TCNQ and absorbing maximally at wavelengths 477 and $841 \mathrm{~nm}$, respectively (Figure 2). The influence of different parameters on the color development was studied to determine optimum conditions.
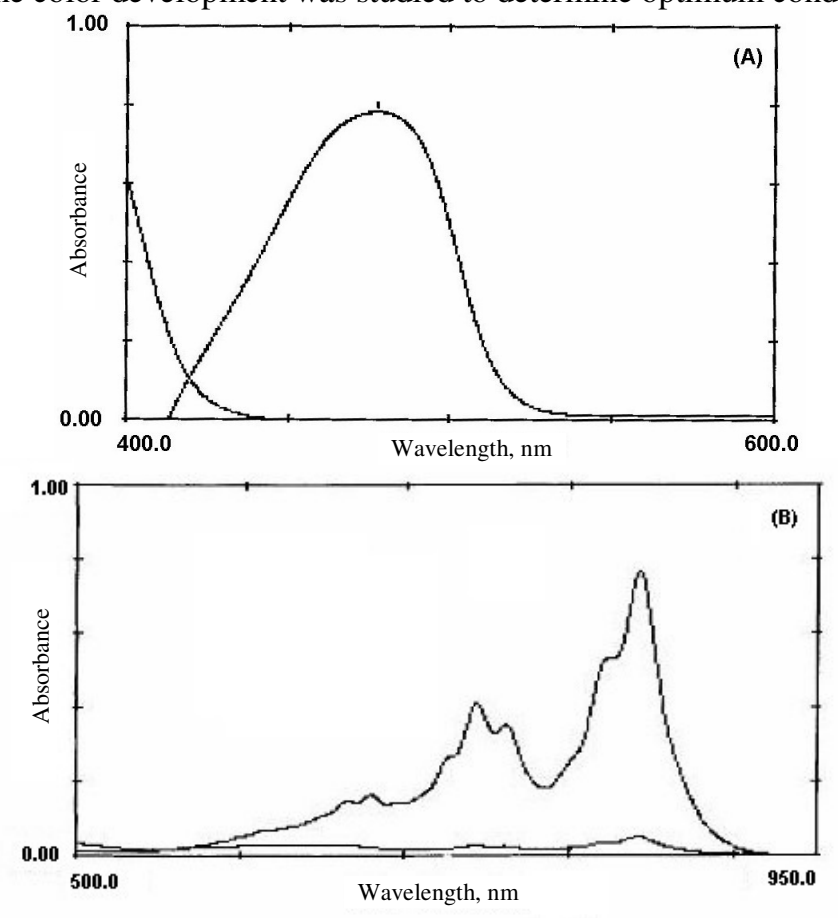

Figure 2(A). Absorption spectrum of $50.0 \mu \mathrm{g} \mathrm{mL} \mathrm{m}^{-1}$ DLX complex with DDQ reagent against reagent blank, (B) Absorption spectrum of $60.0 \mu \mathrm{g} \mathrm{mL}^{-1}$ DLX complex with TCNQ reagent against reagent blank 


\section{Choice of solvent}

Different solvents included chloroform, acetonitrile, acetone, ethanol, 1,4-dioxan, methanol, and methylene chloride were investigated in order to select the suitable solvent. Acetonitrile is considered to be an ideal solvent for the colour reaction as it offers solvent capacity and gives the highest yield of the radical as indicated by high $\varepsilon$ values.

\section{Reagent concentration}

The effect of DDQ and TCNQ concentration (by volume) on its reaction with the DLX were investigated. It is found that, when various concentrations (by volume) of DDQ and TCNQ solution added to a fixed concentration of DLX, $2.0 \mathrm{~mL}$ of TCNQ and $2.5 \mathrm{~mL}$ of DDQ solutions $0.2 \%(\mathrm{w} / \mathrm{v})$ are found to be sufficient for quantitative determination of DLX (Figure 3).

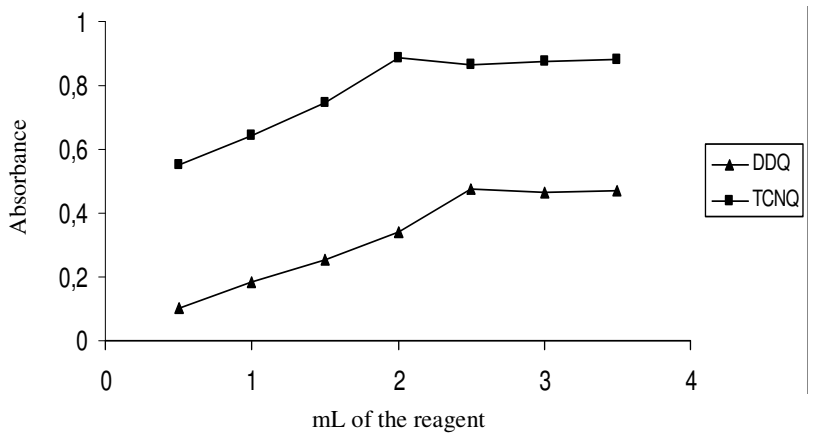

Figure 3. Effect of volume of DDQ, $(0.2 \%$, w/v) and TCNQ $(0.2 \%$, w/v) on the development of the reaction product of DLX with these reagents at $(\boldsymbol{\Delta})$ DDQ and $(\boldsymbol{\square})$ TCNQ.

\section{Reaction time}

The optimum reaction time was determined by following the color development at room temperature and $60-80{ }^{\circ} \mathrm{C}$. Complete color development was attained after 5 min for TCNQ at room temperature, whereas for DDQ, complete color development was obtained after heating on a water bath at $60{ }^{\circ} \mathrm{C}$ for $20 \mathrm{~min}$ (Figure 4). The resultant complexes were stable up to $24 \mathrm{~h}$ at room temperature in the dark.

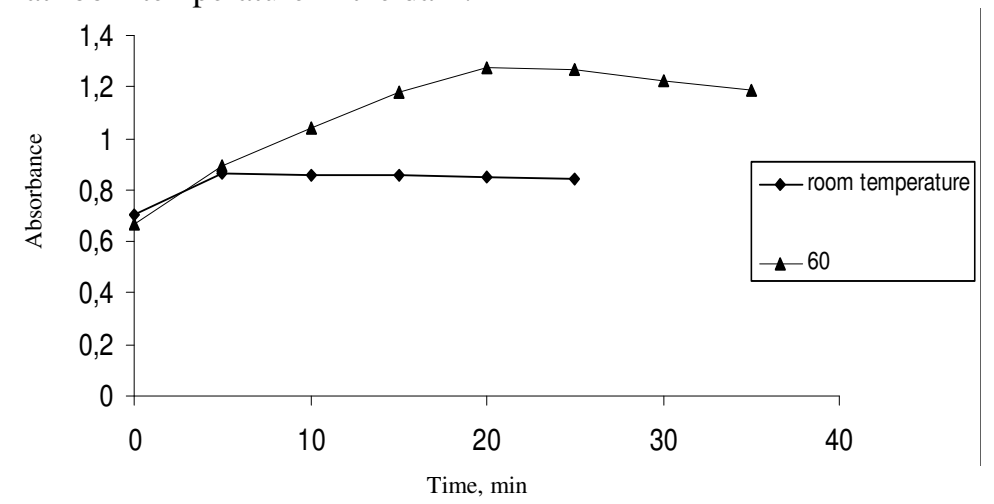

Figure 4. The effect of temperature and time of heating on the reaction between DDQ (at $60{ }^{\circ} \mathrm{C}$ ) and TCNQ (at room temperature) reagents with DLX at ( $\mathbf{\Delta})$ DDQ, ( $)$ TCNQ 


\section{Stoichiometry of the reaction}

The molar ratio of DDQ and TCNQ to DLX in the reaction mixture was studied according to Job's method of continuous variation ${ }^{16}$. Utilizing equimolar solution of DLX and DDQ and TCNQ, the reaction stoichiometry was found to be a good approximation 1:1 ratio (drug/reagent), confirming that one molecule of DLX reacts with one molecule of DDQ or TCNQ.

\section{Method validation}

Linear relationship was found with between the absorbance at $\lambda_{\max }$ and the concentration of the drug in the ranges 10.0-50.0 and 15.0-60.0 $\mu \mathrm{g} \mathrm{mL}^{-1}$ for DDQ and TCNQ method, respectively. Molar absorptivity value of DDQ and TCNQ method was found as $1.60 \times 10^{4}$ and $1.16 \times 10^{4} \mathrm{~L} / \mathrm{mol} . \mathrm{cm}$, respectively. The DDQ method is more sensitive compared with that of the TCNQ method, with a high $\varepsilon$ value. Sandell's sensitivity $(S)$ represents the number of micrograms of the determinant per milliliter of a solution having an absorbance (A) of 0.001 for a path length $(l)$ of $1 \mathrm{~cm}$. Thus, $S=10^{-3} / a=\mu \mathrm{g} \mathrm{cm}^{-2}$ where, $a$ is the specific absorptivity and its value (in $\mathrm{mL} \mathrm{g}^{-1} \mathrm{~cm}^{-1}$ ) corresponds to the determinant in a cuvette with an optical length of $1 \mathrm{~cm}$. Also, $a=(b /$ molecular weight of duloxetine base) $\times 1000$, where $b=$ molar absorptivity $=A / C l$, where $C$ is the molar concentration of the determinant and $l=1 \mathrm{~cm}$ path length. Sandell sensitivity was found as 0.022 and 0.030 $\mu \mathrm{g} \mathrm{cm}^{-2}$ for DDQ and TCNQ method, respectively. The limits of detection (LOD) and limits of quantitation (LOQ) were determined using the formula: $\mathrm{LOD}$ or $\mathrm{LOQ}=\kappa \mathrm{SDa} / \mathrm{b}$, where $\kappa=3$ for LOD and 10 for LOQ, SDa is the standard deviation of the intercept and $b$ is the slope. The inter- and intra-day precision were examined by analysis of drugs for same day and five consecutive days (each $n=5$ ). The RSD values for intra-day precision $0.56,0.78 \%$ and inter-day precision $0.93,1.07 \%$ were found for DDQ and TCNQ methods, respectively which were found indicating good precision. The obtained results are summarized in Table 1.

Table 1. Results of validation parameters for proposed methods

\begin{tabular}{|c|c|c|}
\hline Parameter & Using DDQ reagent & Using TCNQ reagent \\
\hline Linearity range $^{\mathrm{a}}, \mu \mathrm{g} \mathrm{mL}^{-1}$ & $10.0-50.0$ & $15.0-60.0$ \\
\hline Intra-day ${ }^{\mathrm{b}}, \mathrm{RSD} \%$ & 0.56 & 0.78 \\
\hline Inter-day $^{\mathrm{c}}, \mathrm{RSD} \%$ & 0.93 & 1.07 \\
\hline \multicolumn{3}{|l|}{ Regression equation $^{\mathrm{d}}$} \\
\hline Slope \pm SD & $0.018 \pm 0.000216$ & $0.0167 \pm 0.0015$ \\
\hline Intercept $\pm \mathrm{SD}$ & $-0.0836 \pm 0.000911$ & $-0.173 \pm 0.00013$ \\
\hline Correlation coefficient, $r$ & 0.9999 & 0.9994 \\
\hline $\mathrm{LOD}, \mu \mathrm{g} \mathrm{mL}^{-1}$ & 0.199 & 0.294 \\
\hline $\mathrm{LOQ}, \mu \mathrm{g} \mathrm{mL}{ }^{-1}$ & 0.663 & 0.980 \\
\hline
\end{tabular}

${ }^{a}$ Average of six determinations, ${ }^{b} n=5$ correspond to replicate analysis for each level, ${ }^{c}$ Results of five different days, ${ }^{d} A=a+b C$ (where $C$ is the concentration of drug in $\mu g \mathrm{ml}^{-1}, A$ is the absorbance at $\lambda_{\max }$ )

To check accuracy of the proposed methods, the standard addition technique was applied. A different amount of pure sample solution was added to three different concentrations of the standard drug solution and assayed. The percent recovery of the added standard to the assay samples was calculated from:

$$
\text { Recovery } \%=\left[\left(\mathrm{C}_{\mathrm{t}}-\mathrm{C}_{\mathrm{u}}\right) / \mathrm{C}_{\mathrm{a}}\right] \times 100
$$


Where $C_{t}$ is the total concentration of the analyte found; $C_{u}$ is the concentration of the analyte present in the formulation and $\mathrm{C}_{\mathrm{a}}$ is the concentration of the pure analyte added to the formulation. The results of analysis of the commercial dosage forms and the recovery study as shown in Table 2. The average percent recoveries obtained were quantitative (99.92-100.05\%), indicating good accuracy of the methods.

Table 2. Results of recovery studies by standard addition method

\begin{tabular}{|c|c|c|c|c|c|}
\hline Method & $\begin{array}{l}\text { Amount } \\
\text { taken, } \\
\mu \mathrm{g} \mathrm{mL}^{-1 \mathrm{a}}\end{array}$ & $\begin{array}{l}\text { Amount } \\
\text { Added, } \\
\mu \mathrm{g} \mathrm{mL}^{-1}\end{array}$ & $\begin{array}{c}\text { Total amount } \\
\text { found }{ }^{\mathrm{b}} \mu \mathrm{g} \mathrm{mL} \mathrm{L}^{-1} \text { ) } \\
\left(\text { Mean } \pm \text { S.D }{ }^{\mathrm{c}}\right.\end{array}$ & $\begin{array}{c}\text { Recovery, } \\
\%\end{array}$ & $\begin{array}{c}\mathrm{RSD}, \\
\%\end{array}$ \\
\hline \multirow{4}{*}{$\begin{array}{l}\text { Using DDQ } \\
\text { reagent }\end{array}$} & \multirow{4}{*}{10} & 10.0 & $19.950 \pm 0.093$ & 99.50 & 0.47 \\
\hline & & 30.0 & $40.1422 \pm 0.26$ & 100.47 & 0.65 \\
\hline & & 40.0 & $49.910 \pm 0.512$ & 99.78 & 1.03 \\
\hline & & 15.0 & $25.012 \pm 0.18$ & 100.08 & 0.72 \\
\hline \multirow{2}{*}{$\begin{array}{l}\text { Using TCNQ } \\
\text { reagent }\end{array}$} & \multirow{2}{*}{10} & 30.0 & $39.950 \pm 0.345$ & 99.83 & 0.86 \\
\hline & & 50.0 & $60.123 \pm 0.321$ & 100.25 & 0.53 \\
\hline
\end{tabular}

${ }^{a}$ Cymbalta capsule®, containing $60 \mathrm{mg}$ of duloxetine per tablets, ${ }^{b}$ Five independent analyses. ${ }^{c}$ Standard deviation

The applicability of the proposed method was tested by the determination of drugs in their pharmaceutical preparations. The results obtained are satisfactorily accurate and precise as indicated by the excellent \% recovery and RSD $<2$ (Table 3). Experiments showed that there was no interference from the additions and excipients, e.g. lactose, glucose, fructose, magnesium stearate and starch.

Table 3. Analysis of DLX in capsules $(n=5)$

\begin{tabular}{ccc}
\hline${\text { Method } 1^{\text {a }}}$ & Using DDQ reagent & Using TCNQ reagent \\
\hline Mean $^{\mathrm{b}} \pm$ S.D & $60.47 \pm 0.47$ & $60.49 \pm 0.51$ \\
Recovery, \% & 100.78 & 100.82 \\
RSD, \% & 0.78 & 0.85 \\
${ }^{a}$ Cymbalta capsule ${ }^{\circledR}$, containing 60 mg of duloxetine per tablets, ${ }^{b}$ five independent analyses
\end{tabular}

\section{Conclusion}

Two simple and less time consuming visible spectrophotometric methods using DDQ and TCNQ reagents were described for analysing of DLX in tablets. DDQ method was the more sensitive than TCNQ method, with a high $\varepsilon$ value $\left(1.60 \times 10^{4} \mathrm{~L} / \mathrm{mol} \mathrm{cm}\right)$. The proposed visible spectrophotometric methods are simple, accurate and highly cost-effective and suitable for routine determination of the duloxetine in capsules.

\section{References}

1. Tran P V, Bymaster F P, McNamara R K and Potter W Z, J Clin Psychopharmacol., 2003, 23(1), 78-86.

2. Pitsikas N, Curr Opin Invest Drugs, 2000, 1(1), 116-121.

3. Wong D T, Exp Opin Invest Drugs, 1998, 7(10), 1691-1699.

4. Bech P, Kajdasz D K and Porsdal V, Psychopharmacology (Berl)., 2006, 188, 273-280.

5. Mallinckrodt $\mathrm{C} \mathrm{H}$, Watkin $\mathrm{J}$ G, Liu $\mathrm{C}$, Wohlreich $\mathrm{M} \mathrm{M}$ and Raskin $\mathrm{J}, B M C$ Psychiatry, 2005, 1, 5. 
6. Skinner M H, Kuan H Y, Skerjanec A, Seger M E, Heathman M, O’Brien L, Reddy S and Knadler M P, Br J Clin Pharmacol., 2004, 57(1), 54-61.

7. Kamila M M, Mondal N and Ghosh L K, Pharmazie, 2007, 62, 414-415.

8. Dhaneshwar S S, Deshpande P, Patil M, Vadnerkar G and Dhaneshwar S R, Indian J Pharm Sci., 2008, 70(2), 233-236.

9. Chhalotiya U K, Bhatt K K, Shah D A and Baldanıa S L, Sci Pharm., 2010, 78(4), 857-888.

10. Foster R, Organic Charge-Transfer Complexes, Academic Press, London, 1969, 94.

11. Melby L R, In: Patai S (Editor), The Chemistry of the Cyano Group, Interscience, New York, 1970, 639-670.

12. Rahman N, Khan N A and Azmi S N H, Anal Sci., 2004, 20, 1231.

13. Rao C N R, Bhat S N, Dwivedi P C, In: Brame E G (Editor) Applied Spectroscopy Reviews Dekker, New York, 1972, 5, 1-170.

14. Basavaiah K, IL Farmaco, 2004, 59, 315.

15. Saleh G A, Askal H F, Darwish L A and El-Shorbagi A N A, Anal Sci., 2003, 19(2), 281-287.

16. Job P, Ann Chem., 1928, 9, 113. 


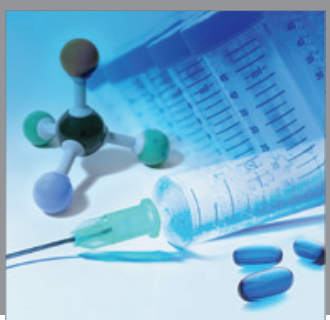

International Journal of

Medicinal Chemistry

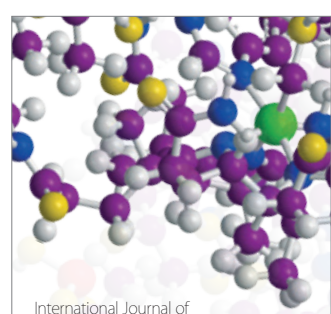

Carbohydrate Chemistry

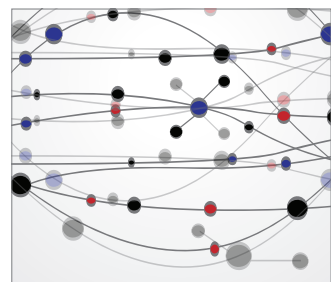

The Scientific World Journal
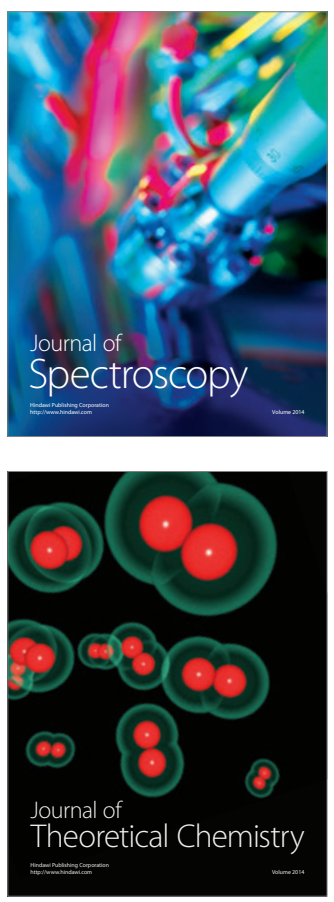
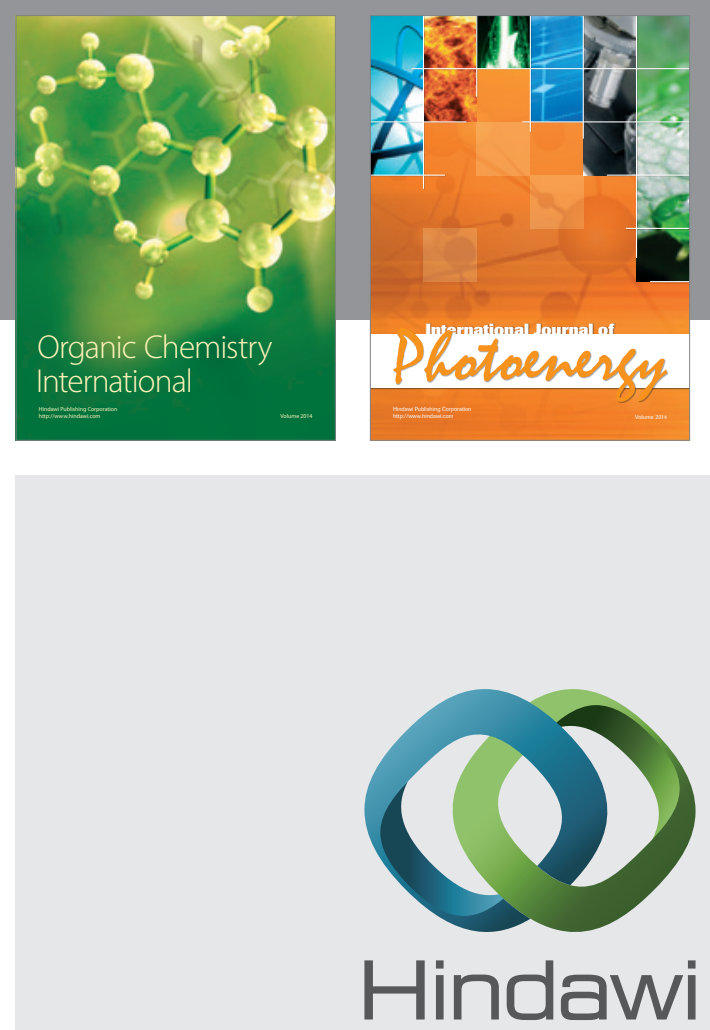

Submit your manuscripts at

http://www.hindawi.com
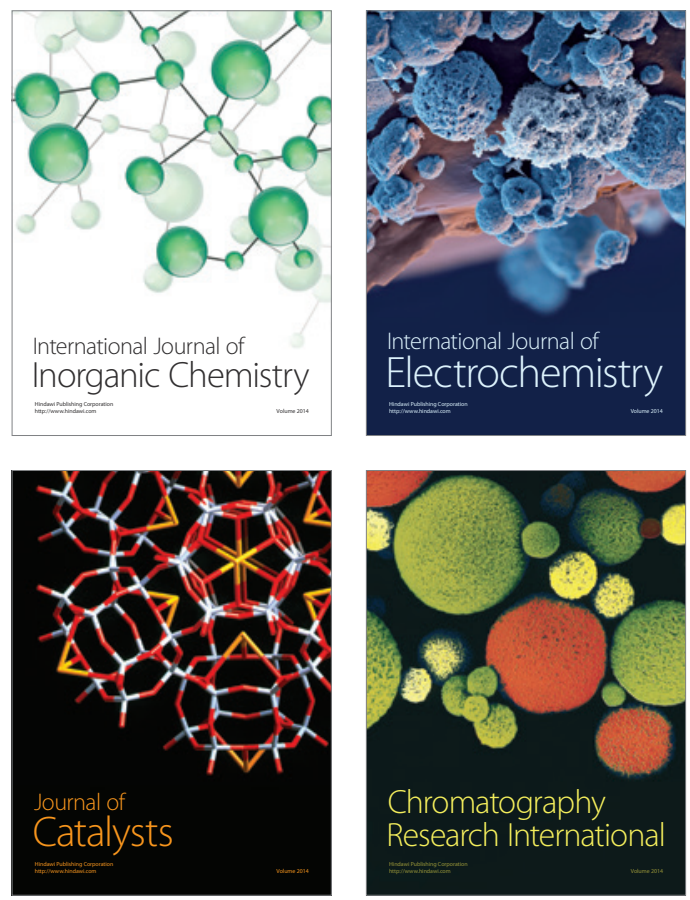
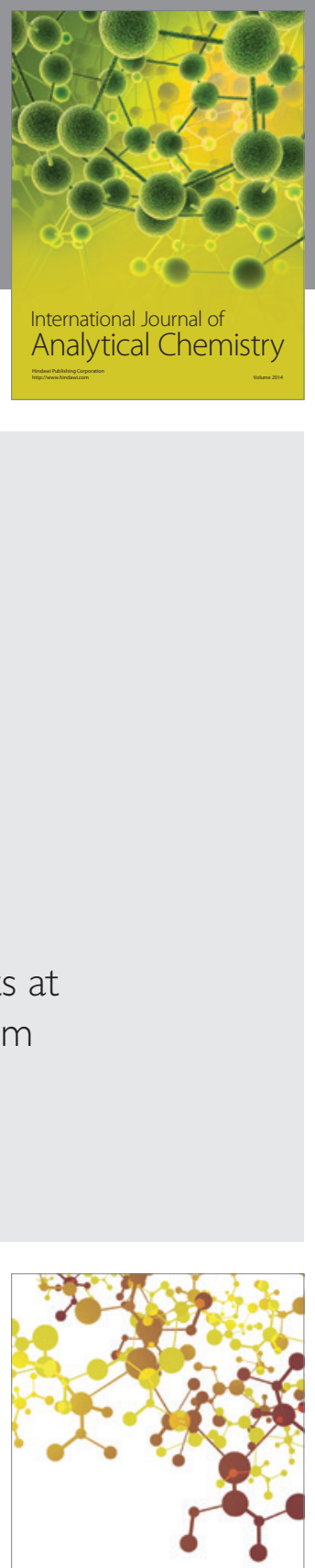

Journal of

Applied Chemistry
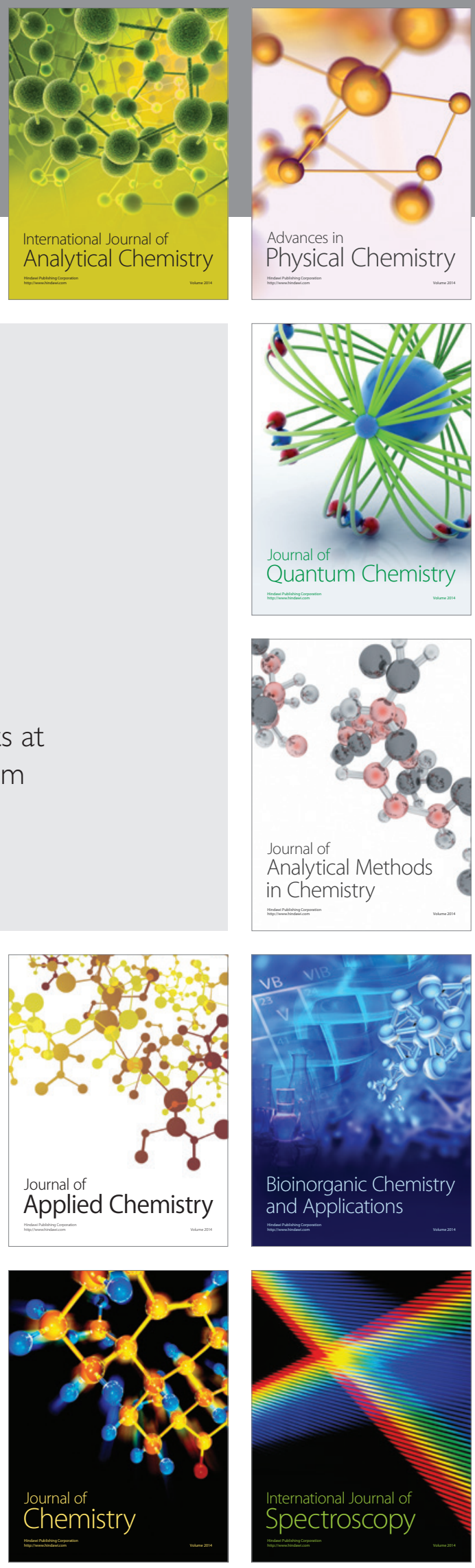